\title{
PROBLEMATIQUE DE L'UTILISATION DES ENGRAIS MINERAUX DANS LES ZONES DE PRODUCTION DU RIZ : CAS DU CENTRE-OUEST DE LA CÔTE D'IVOIRE.
}

\author{
J. T. B. GALA ${ }^{1}$, M. CAMARA ${ }^{1}$, A. ASSA ${ }^{2}$, J. Z. KELI ${ }^{1}$ \\ ${ }^{1}$ Ingénieur Agronome, Doctorant - CNRA, 01 BP 1740 Abidjan 0. E-mail : gala_trazie@yahoo.fr / \\ camara_mameri@yahoo.fr \\ 2 Université de Cocody / Abidjan
}

\begin{abstract}
RESUME
Dans le but de mettre au point de barèmes de fumure minérale adaptés aux régions et aux variétés nouvelles de riz pluvial, une enquête a été réalisée à Saïoua, auprès de 7 associations de riziculteurs dans le Centre Ouest de la Côte d'Ivoire. Cette enquête a porté sur les riziculteurs et leur environnement, les caractéristiques des systèmes de culture à base de riz pluvial, la perception et l'utilisation des engrais chimiques et, enfin, la destination de la production rizicole. II ressort de l'enquête que la production de riz est à dominance destinée à l'autoconsommation. La riziculture pluviale, activité la plus répandue dans la région, est pratiquée à $95 \%$ par les femmes. Elle demeure encore itinérante, avec apparition, localisée de zones de blocage foncier. Cette situation a entraîné l'éloignement des parcellesrizicoles des villages et une exploitation continue de certaines parcelles pendant 2, voire 3 ans. les pratiques agricolesont entrainé la nécessité de de restaurer les terres cultivées à travers l'utilisation des engrais chimiques selon les paysans. Aussi, le souhait des trois quarts des riziculteurs enquêtés est-il d'utiliser ces engrais chimiques. Mais, compte tenu du coût élevé et de la faiblesse du pouvoir d'achat de la population rurale, les engrais ne sont pas effectivement utilisés. Les quelques riziculteurs enquêtés, qui ont déjà utilisés les engrais chimiques, ont obtenu les produits par le biais d'Organisations Non Gouvernementales (ONG) à la faveur de projets agricoles.
\end{abstract}

Mots clés : riziculture pluviale, enquête, engrais chimiques, Côte d'Ivoire.

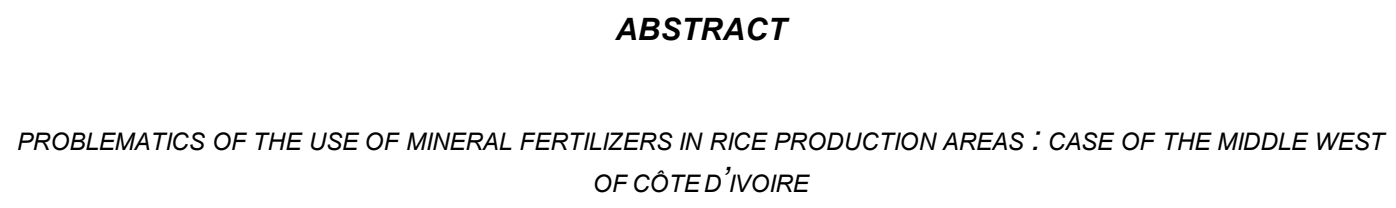

In order to define appropriate fertilizer rates for new rice varieties in the different areas of rainfed rice production, a survey was conducted in Saïoua, mid-west Côte d'lvoire. Seven rice farmer associations were surveyed. Parameters, such as: upland rice-based systems and market chracteristics, as well as farmer social status and perceptions toward mineral fertilizer use were assessed. Results show that: $95 \%$ of rice farmers were women and cropping systems itinerant. This led to land scarcity, remoteness of production sites with respect to thomes, as well as land overuse (3-4 years of continuous cropping on the same land). Mineral fertilizer addition to soil appears to be the solution to this problem. For most farmers (75\%), beside fallows systems, chemical fertilizer additions appear to be the only way out to improve soil quality. However, because of high chemical fertilizers cost, which is often out of reach of most farmers, fertilizers are not properly used by farmers and production is aimed at self-consumption. The few farmers who used fertilizers in their plots obtained those amendements from local NGOs through agricultural projects implemented in the area.

Key words : upland rice farming, inquiry, mineral fertilizers, Côte d'Ivoire. 


\section{INTRODUCTION}

Le riz est aujourd'hui l'une des céréales la plus consommée dans le monde (FAO, 2002). II devient de plus en plus l'aliment de préférence des populations africaines (FAO, 2004). La demande de riz en Afrique de l'Ouest et du Centre croît de $6 \%$ par an (ADRAO, 2002). Cette croissance est plus élevée que partout ailleurs dans le monde. Aussi, la production rizicole locale des différents pays africains ne compense pas les besoins de consommation de cette denrée (Norman et Otoo, 2003). Ce constat est valable pour la Côte d'Ivoire qui bénéficie pourtant de potentialités naturelles pouvant lui permettre d'assurer la sécurité alimentaire par une production locale (Riquier, 1971 ; Banque Mondiale, 1982 ; Hirsch, 1984).

Cependant, pour atteindre cet objectif de sécurité alimentaire, plusieurs vagues d'introduction de nouvelles variétés de riz et de fiches techniques y afférentes ont eu lieu en Côte d'Ivoire dont les dernières ont été réalisées à travers des projets tels que Community Based Seed System (CBSS), Participate Varietal Selection (PVS) et Riz pour tous exécuté sur le terrain grâce à l'appuie des Organisations Non Gouver-nementales comme par exemple I'Organisation des Volontaires du Développement Local ( N'Cho et Konaté, 2001 ; 2004).

La riziculture pluviale, mode de production le plus pratiqué en Côte d'Ivoire avec plus de $90 \%$ des superficies emblavées et $80 \%$ de la production nationale, reste encore de type traditionnel, extensif et itinérant. Ce type de riziculture est pratiqué sur de nouvelles défriches pour bénéficier de la fertilité naturelle des sols pendant au plus deux ans.

Pour faire face à la baisse de fertilité qui découle de ce mode d'exploitation, plusieurs solutions ont été proposées, notamment :

- la fertilisation minérale qui permet de compenser les carences en azote, en phosphore et en potassium (Saragoni et al., 1992). Cette méthode, quoique efficace, n'est appliquée qu'en riziculture de bas-fond à cause du coût élevé des produits chimiques (Eponou, 1983) ;

- la fertilisation organique avec la jachère améliorée par les légumineuses (Gnahoua, 1997 ; Becker et Johnson, 1998 ; Autfray et Gbakatchétché, 1998 ; Harmand et Ballé,
2001 ; Melendez et al., 2003), le compost, les engrais verts, le fumier, la fiente de volaille et le purin (Dupriez et De Leener, 1986 ; Akanza et Yoro, 2003). Ces différentes techniques de fertilisation organiques ont des potentialités intéressantes qui ne sont pas mises en valeur dans la riziculture pluviale ;

- des techniques culturales tels que l'association (Keli et al.,1990), l'assolement et la rotation (Becker et Johnson, 1998 ; Autfray et Gbakatchétché, 1998 ; Ryser et Pittet, 2002 ; Kouadio, 2003).

De toutes les solutions qui précèdent, la fertilisation minérale demeure incontournable (Bationo et Somda, 1994). Or à l'exception des projets agricoles ponctuels où les riziculteurs reçoivent gratuitement les engrais chimiques, très peu d'indices renseigne sur l'utilisation des engrais minéraux en riziculture pluviale de plateau qui est la pratique rizicole la plus courante.

La présente étude a pour objectif l'obtention de statistiques sur l'utilisation des engrais minéraux en riziculture pluviale de plateau. Ces données permettront une meilleure compréhension de la perception qu'ont les riziculteurs ruraux des engrais chimiques.

\section{MATERIELS ET METHODES}

\section{ECHANTILLONNAGE}

La population cible est celle des riziculteurs de la zone de Saïoua. Deux villages (Tézié et Godoua) ont été choisis à la suite des résultats d'enquêtes générales sur les pratiques agricoles dans la zone. Tézié est une zone où la pression foncière s'installe à l'image d'autres régions de la Côte d'Ivoire (Charpentier et al., 1999), tandis que Godoua ne semble pas encore être touché par ce problème.

L'enquête a duré environ un an, de décembre 2004 à décembre 2005. La zone de l'étude constitue l'une des plus grandes zones de production rizicoles du pays.

Pour mener à bien cette enquête parmi les riziculteurs, la méthode du choix raisonné a conduit à travailler préférentiellement avec les membres des associations de riziculteurs. Ainsi, les membres présents desdites associations 
(cinq associations à Tézié et deux à Godoua) ont été interrogés. Dans chacun des villages, les associations sont regroupées en union associative. Au total, 98 riziculteurs ont été enquêtés, soit $44 \%$ de la population totale.

\section{METHODE D'ENQUETE}

L'enquête a été réalisée à travers un questionnaire semi-ouvert. Les points principaux pris en compte sont l'enquêté et son environnement social, la caractérisation et la gestion du patrimoine foncier, l'utilisation et la perception des intrants chimiques.

Les revendeurs de produits agrochimiques qui sont au nombre de 6 dans la zone ont également été enquêtés par interview.

Les principaux résultats recherchés sont :

- le pourcentage de riziculteurs qui connaissent les engrais chimiques,

- le pourcentage de riziculteurs qui utilisent les engrais chimiques,

- la quantité d'engrais chimique que peut acquérir un riziculteur.

\section{RESULTATS}

\section{LES CARACTERISTIQUES DES ENQUETES}

Dans la région de l'enquête, la riziculture pluviale de plateau est pratiquée essentiellement par les femmes. En effet, l'enquête a montré que la riziculture pluviale de plateau est pratiquée à $95 \%$ par les femmes. Et parmi ces femmes, $4 \%$ sont des allochtones qui ont contracté des liens de mariage avec les autochtones bété.

Seuls les hommes autochtones pratiquent la riziculture pluviale de plateau (5\% de l'effectif).

Dans notre échantillon, $42 \%$ des personnes enquêtées sont âgées de 20 à 40 ans, tandis que $49 \%$ des paysans sont âgés de 40 à 60 ans. Les personnes de plus de 60 ans représentent $9 \%$ de l'effectif. (Figure 1).

Tous les riziculteurs ont au moins une personne en charge. Parmi ceux-ci, $44 \%$ ont plus de cinq enfants en charge, $28 \%$ ont 4 enfants et seulement $6 \%$ n'ont qu'un enfant en charge (Figure 2).

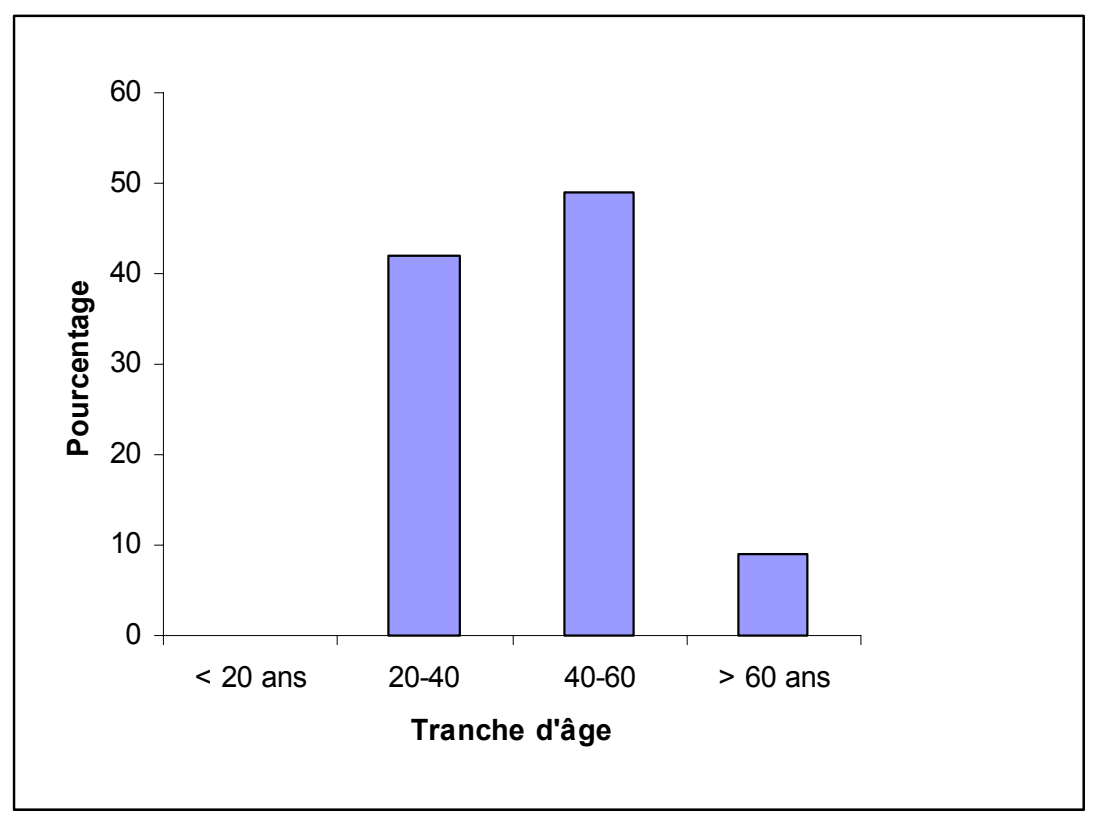

Figure 1 : Tranche d'âge des enquêtés.

Age of group of farmers interviewed. 


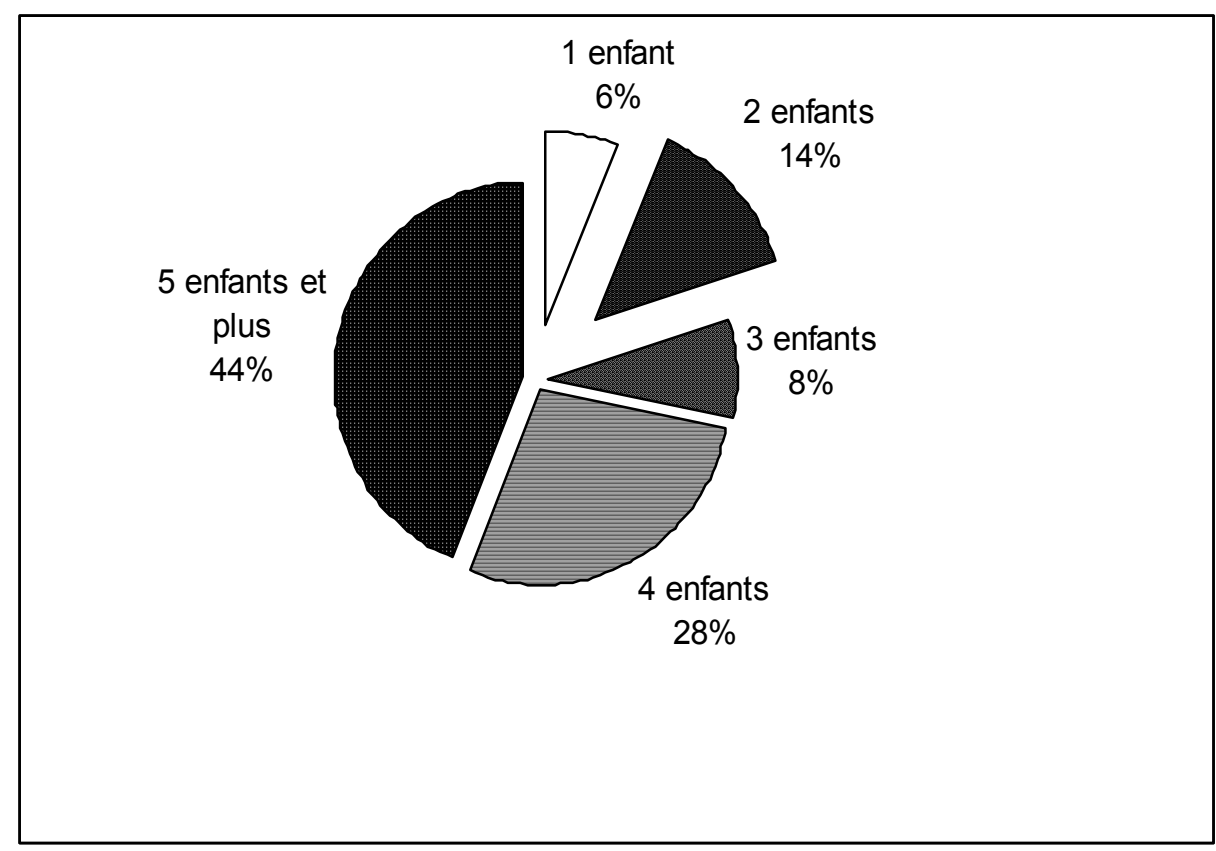

Figure 2 : Nombre d'enfants à la charge du riziculteur.

Number of Childreen in charge of the rice farmers.

\section{LES CARACTERISTIQUES GENERALES DES PARCELLES CULTIVEES.}

\section{L'éloignement des parcelles cultivées}

De manière générale, il ressort de l'enquête que plus de $50 \%$ des parcelles cultivées en riz pluvial de plateau sont situées à moins de $3 \mathrm{~km}$ du village. II faut relever qu'à Godoua, la quasitotalité des enquêtés ont leurs champs de riz situés à moins de $5 \mathrm{~km}$, tandis qu'à Tézié, seulement $14 \%$ des champs sont au-delà de $5 \mathrm{~km}$.

\section{Les indicateurs pris en compte pour la mise en valeur des jachères}

Les indicateurs pris en compte par les riziculteurs pour la mise en valeur des jachères sont l'âge de la jachère, l'abondance de la matière végétale sèche sur les parcelles, l'apparition de certaines espèces végétales (telles que Chromoleana odorata et les dicotylédones en générale), la hauteur de la végétation et l'activité de la faune du sol (Figure 3).

L'âge de la jachère est de loin l'indicateur le plus cité par les paysans (69\%) pour apprécier la remise en valeur ou non d'une parcelle donnée. $19 \%$ des enquêtés se fondent sur l'aspect de la végétation. Et les éléments pris en compte au niveau de la végétation pour identifier une jachère restaurée sont la grande taille des arbustes et des arbres et la présence des lianes.

Pour $3 \%$ des exploitants l'abondance de la matière végétale à la surface du sol est signe de l'évolution positive de la jachère. Et $2 \%$ évoquent l'activité de la faune du sol notamment la présence des turricules de vers de terre et des galeries des fourmis.

Pour $7 \%$ des exploitants, la mise en valeur d'une jachère n'est fondée sur aucun des facteurs cidessus évoqués. Dans ce dernier cas, les paysans se contentent de la terre mise à leur disposition.

\section{L'âge de la jachère avant la mise en culture.}

A Godoua, $10 \%$ des enquêtés disent disposer encore non seulement des forêts primaires mais en plus des jachères de plus de 5 ans d'âge. Alors qu'à Tézié, il est souligné l'inexistence de jachères de plus de 5 ans.

II faut relever à partir de ce qui précède que la plupart des enquêtés se réfèrent au chiffre 5 , durée de la jachère, pour sa remise en valeur (Figure 4). II faut souligner que pour $3 \%$ des exploitants les jachères peuvent avoir plus de 5 ans avant leur remise en culture. 


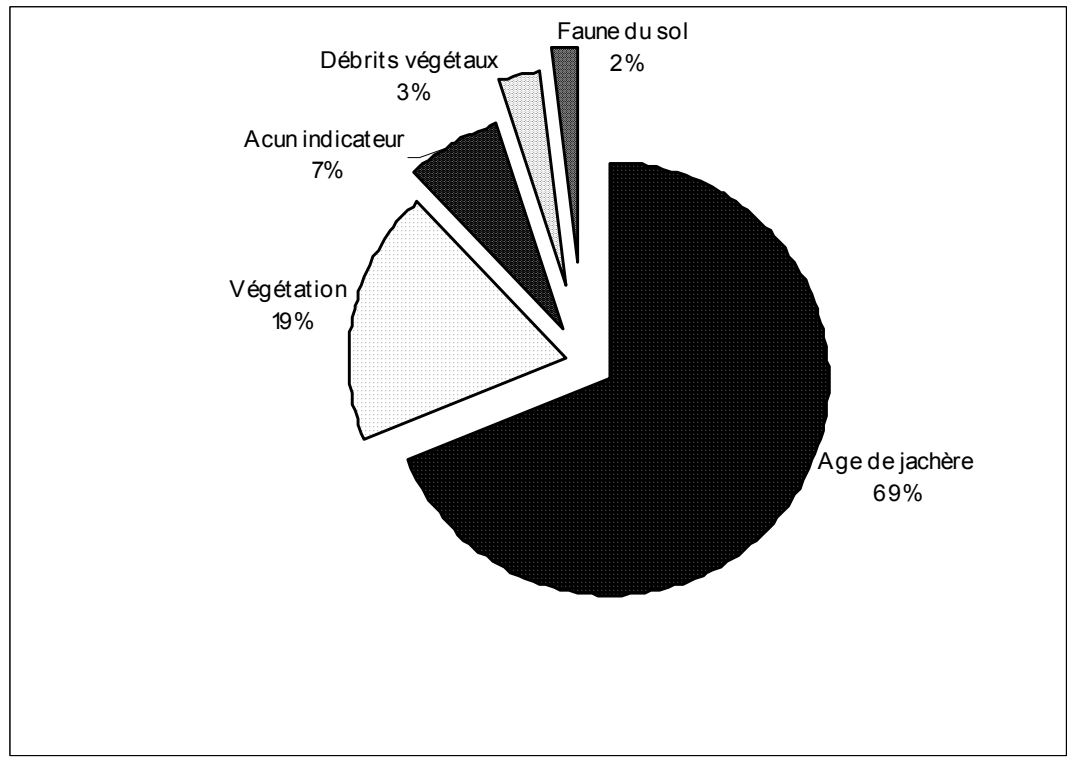

Figure 3 : Indicateurs observés pour la mise en valeur des jachères.

Indicators observed before tilling fallow paid.

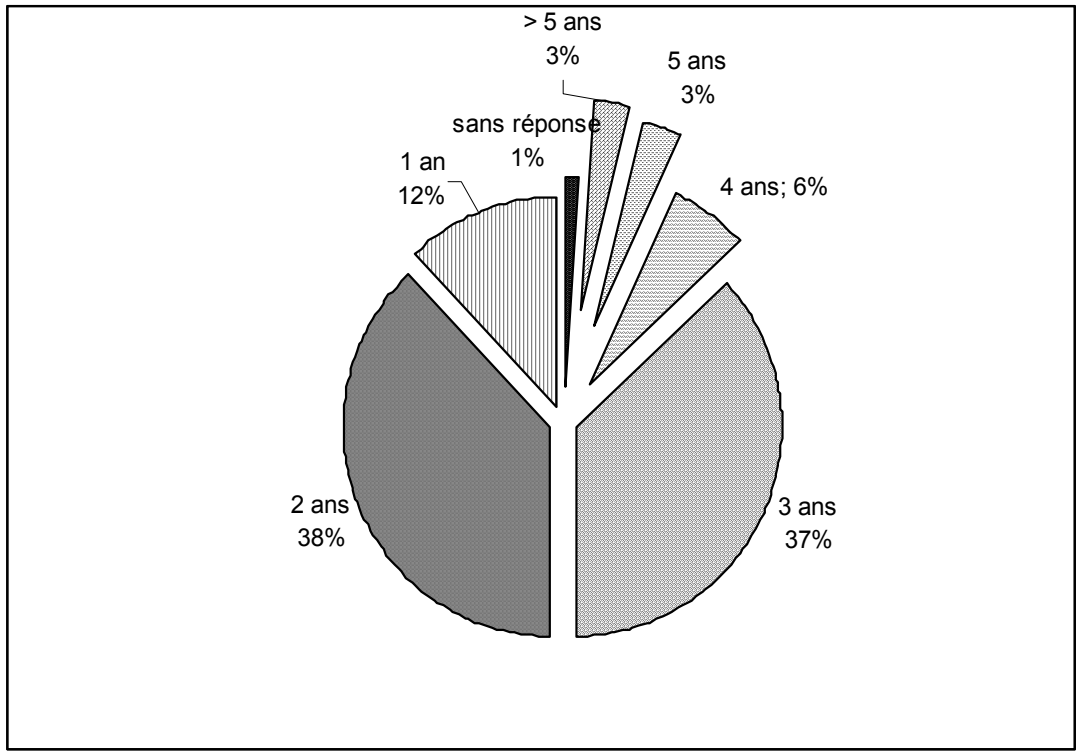

Figure 4 : Age de la jachère avant la remise en culture.

Fallow age before soil tilling for rice cultivation.

La durée moyenne des jachères dans la région de Saïoua varie de 1 à 4 ans. En effet, l'enquête révèle que la durée de la jachère de 4 ans représente $6 \%$, de 3 ans $37 \%$, de 2 ans $38 \%$ et de 1 an $12 \%$. Les pourcentages cumulés des jachères reprises après 2 et 3 ans s'élève à $75 \%$.

La proportion des enquêtés qui n'a pas exprimé d'opinion $(1 \%)$ représente la frange des riziculteurs qui ne disposent pas de terre. II s'agit essentiellement de quelques veuves qui n'ont plus accès à la terre après le décès de leur mari.

\section{La durée d'exploitation des terres.}

Près de deux tiers (63\%) des riziculteurs enquêtés n'exploitent une nouvelle parcelle que pendant seulement une seule année. En cas de nécessité, la moitié de ceux-ci (32\%) peut 
exploiter suite la même parcelle pendant 2 ans au plus. Une frange infime (5\%) des enquêtés affirme cultiver la même parcelle en riz pendant 3 années consécutives (Figure 5).

Si l'on considère la proportion des exploitants qui cultive la même parcelle en riz pendant une à deux années consécutive l'on arrive à un pourcentage cumulé de $95 \%$. II faut souligner que $10 \%$ de ce pourcentage reconnaissent que les rendements chutent d'environ $30 \%$ en deuxième année et plus de $75 \%$ en troisième année.

\section{LA QUALITE DES TERRES CULTIVEES EN RIZ.}

\section{Les problèmes des terres cultivées par le paysan.}

$28 \%$ des riziculteurs reconnaissent que les objectifs de production qui sont l'autoconsommation durant toute l'année et la commercialisation d'une partie de la production en cas de besoin ne sont pas atteints. Les causes évoquées par les paysans pour expliquer la non satisfaction des objectifs sont, entres autres, la qualité médiocre des terres exploitées, la baisse de la fertilité du sol et la pression des plantes adventices (Figure 6). En effet, selon $8 \%$ des enquêtés, la pauvreté du sol est le premier facteur limitant de la production du riz, tandis que pour $30 \%$ des enquêtés elle constitue l'une des principales contraintes.

$27 \%$ considèrent l'enherbement comme le premier facteur limitant. Deux tiers de ce dernier pourcentage affirment que le taux élevé d'enherbement est la manifestation visible de la pauvreté du sol.

\section{Les indicateurs de la pauvreté des sols selon les riziculteurs.}

La figure 7 présente les indicateurs de la baisse de la fertilité des sols.

$3 \%$ des riziculteurs ignorent tout indicateur de pauvreté du sol.

Pour $2 \%$ des enquêtés, la décoloration de la couleur initiale du sol traduit généralement la baisse de la fertilité du sol. $8 \%$ des enquêtés estiment que l'absence de la faune dans un sol notamment les vers de terre et les termites est un signe de pauvreté de sol.

Une proportion identique de $8 \%$ pense que des phénomènes comme la coloration jaunâtre des feuilles, des arbustes rabougris et la prépondérance des graminées sur une parcelle sont également des signes de pauvreté du sol.

Un sol cohérent c'est-à-dire qui ne peut être cassé avec la main voire compact (qui peut être cassé avec un marteau), pourrait, selon les enquêtés, avoir une faible réserve d'eau pour la plante. Ainsi, $27 \%$ des riziculteurs affirment que les sols cohérents ne sont pas propices à la riziculture.

En plus des facteurs ci-dessus évoqués, plus de la moitié des riziculteurs (52\%) se fondent sur l'aspect du riz en phase végétative et sur le taux d'enherbement de la parcelle. Pour ceuxci, le sol est pauvre quand l'enherbement est excessif dans le champ de riz, ou lorsque le riz en végétation est de petite taille, avec une coloration jaune pâle et que le rendement est faible.

\section{LES MOYENS DE RESTAURATION DE LA FERTILITE DU SOL CONNUS ET PRATIQUES PAR LE PAYSAN}

Les moyens de restauration de la fertilité du sol les plus connus des riziculteurs sont la mise en jachère des parcelles et l'utilisation d'engrais chimiques. Seulement $3 \%$ des riziculteurs enquêtés connaissent les légumineuses dans leur rôle de la restauration de la fertilité du sol.

PERCEPTIONDES ENGRAIS MINERAUXPAR LES PRODUCTEURS DU RIZ PLUVIAL DE PLATEAU

\section{Les connaissances des engrais chimiques par les riziculteurs}

II ressort des enquêtes que les engrais chimiques sont connus de tous les exploitants. Cependant, $39 \%$ les ont appliqués sur d'autres cultures, précisément sur le cacao et les cultures maraîchères et $21 \%$ les ont connus pour les avoir utilisés sur le riz dans l'exécution de certains projets (CBSS et Riz Pour Tous). Et $40 \%$ des riziculteurs ont entendu parler des engrais minéraux. 


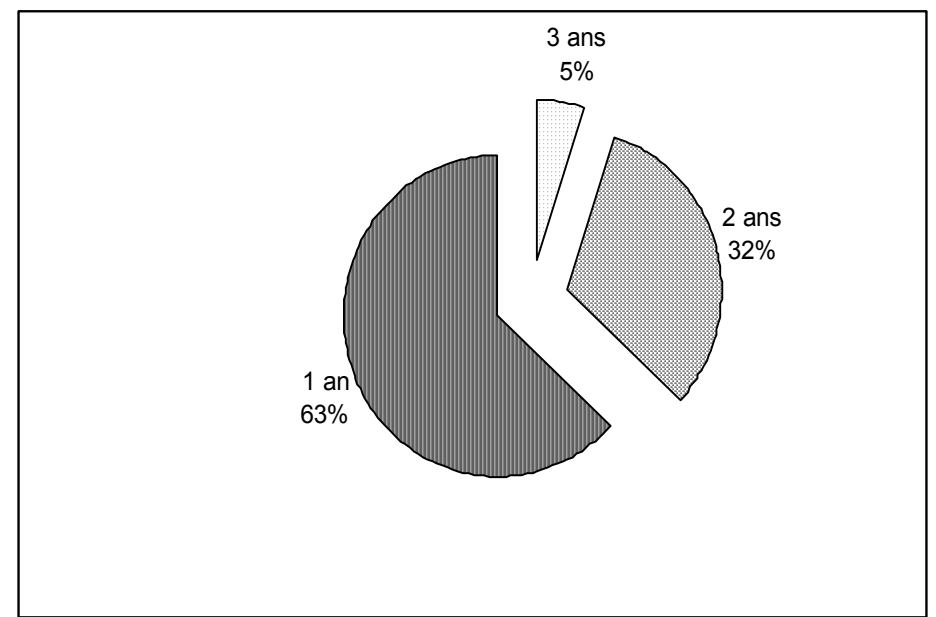

Figure 5 : Durée d'exploitation des terres en riz avant la mise en jachère.

The duration of soil use for rice cultivation belore fallow.

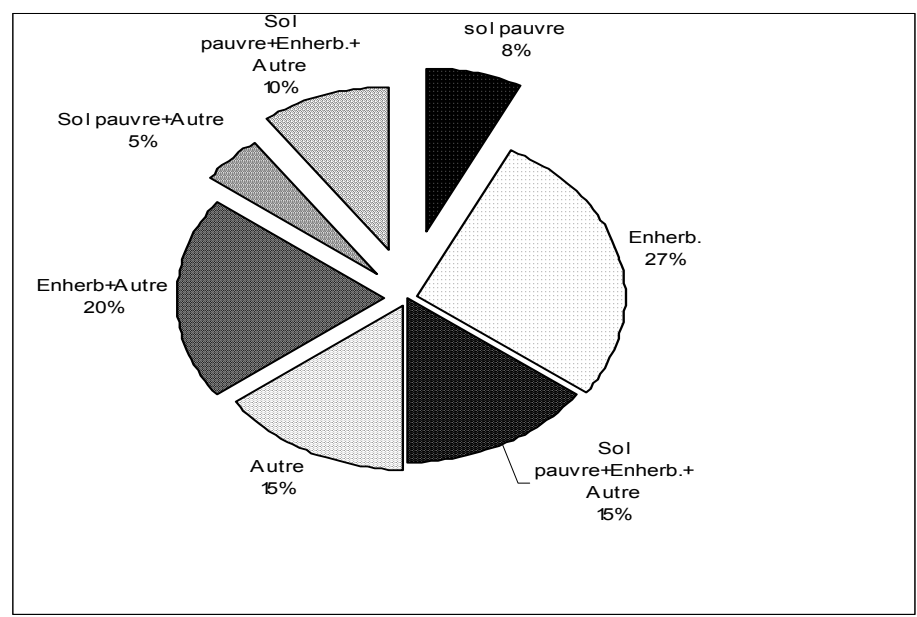

Figure 6 : Problèmes observés sur les terres rizicultivées.

Problems on tilling soil according to farmers.

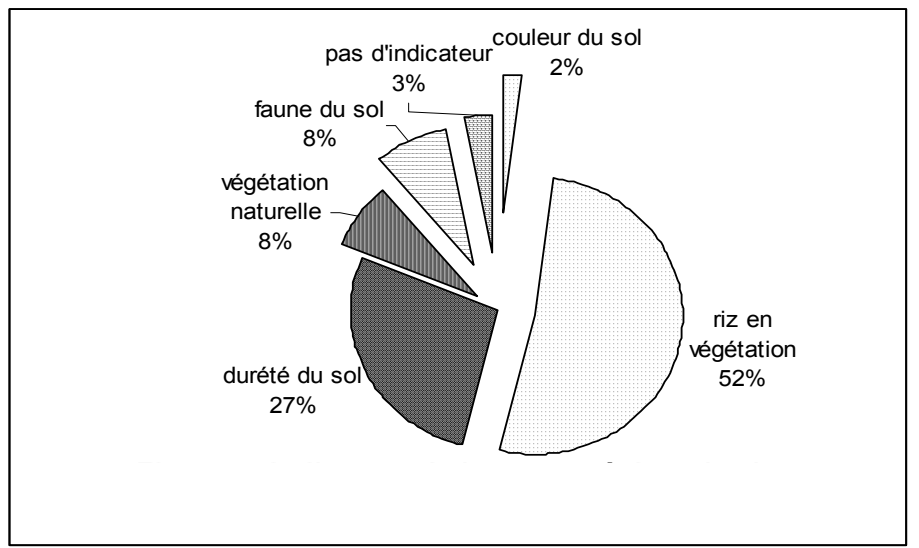

Figure 7 : Indicateur de la pauvreté du sol selon les riziculteurs.

Barren soil indicators according to rice farmers. 


\section{Les engrais chimiques vus par les riziculteurs}

$4 \%$ des enquêtés confondent le rôle des engrais chimiques et celui des herbicides. L'itinérance de la riziculture conduit une frange des enquêtés (10 \%) à affirmer n'avoir jamais constaté les effets bénéfiques de l'utilisation des engrais chimiques sur le riz pluvial.

Si $23 \%$ des enquêtés disent ignorer le rôle des engrais chimiques, il faut relever que $63 \%$ reconnaissent que les engrais chimiques améliorent la qualité du sol en procurant un bon rendement (Figure 8).

Malgré l'importance de ce pourcentage (63\%), l'enquête révèle que le quart des riziculteurs est réticent à l'utilisation des engrais chimiques en riziculture pluviale de plateau pour diverses raisons (Figure 9).

Parmi ces raisons, l'on peut retenir :

- le manque d'informations précises sur le mode d'utilisation des engrais chimiques en riziculture pluviale (33\%),

- l'utilisation des engrais chimiques favorise l'enherbement excessif des parcelles (33\%),

- les contraintes climatiques notamment la sécheresse $(17 \%)$ qui ne permet pas de valoriser les apports d'engrais chimiques,

- l'indifférence (17\%) qui représente la proportion de ceux qui n'émettent pas d'avis sur l'utilisation des engrais chimiques.

\section{UTILISATIONDES ENGRAIS CHIMIQUES PAR LES PRODUCTEURS DU RIZ PLUVIAL DE PLATEAU}

\section{Les types d'engrais chimiques connus des paysans}

L'engrais chimique connu et déjà utilisé par les paysans est l'urée contenant $46 \%$ d'azote. Tous ceux qui ont utilisé l'urée, l'ont obtenu sous forme de don d'une Organisation Non Gouvernementale (ONG) dénommée Organisation des Volontaires du Développement Local (OVDL) dont les activités s'inscrivent dans le cadre de l'exécution des projets.
Les périodes d'application et les variétés de riz bénéficiant des apports d'engrais chimique

L'enquête a montré que les engrais chimiques offerts par l'ONG ne sont appliqués que sur les variétés améliorées de riz à cycle court (NERICA, IDSA85) et de cycle moyen (WAB56-50) environ 30 jours après le semis ou à l'épiaison lorsque le paysan fait une seule application. S'il doit faire deux apports d'engrais, les données recueillies montrent que la première application intervient entre le $30^{\circ}$ et le $35^{\circ}$ jour après le semis et la deuxième application à l'épiaison. Ces applications sont faites sur les conseils des agents de l'ONG.

\section{L'environnement socioéconomique des engrais chimiques utilisés en riziculture pluviale de plateau}

Un écart entre vœux et utilisation effective des engrais chimiques.

Le souhait des trois quarts des riziculteurs est d'utiliser les engrais chimiques dans la culture du riz pluvial de plateau. Compte tenu de leur pouvoir d'achat, ce souhait reste au stade de vœu.

Et une projection faite sur l'achat des engrais chimiques par les riziculteurs enquêtés montre que la moyenne des efforts financiers que ces derniers sont près à consentir s'élève à 4000 FCFA.

Les propos recueillis auprès des revendeurs de produits agrochimiques montrent que :

- les engrais chimiques en riziculture pluviale de plateau ne bénéficient pas d'une filière de crédits pour les riziculteurs individuels comme c'est le cas de certaines cultures de rente telles que le coton ;

- l'engrais HYDRORIZ mis au point par Yara West Africa qui dit-on satisfait aux besoins du riz cultivé dans les écosystème de bas-fond et de plateau sont méconnus des riziculteurs pour la raison qu'aucune demande n'a été enregistrée chez les revendeurs;

- l'objectif de production des enquêtés étant surtout l'autoconsommation, ces derniers 
continuent de pratiquer la riziculture itinérante sur brûlis.

\section{Les objectifs de production}

La figure 10 représente les objectifs que les riziculteurs se fixent avant la mise en place de leur champ de riz. $64 \%$ de ces riziculteurs produisent le riz pluvial de plateau pour l'autoconsommation exclusivement. $27 \%$ sont disposés à vendre le surplus de production après satisfaction de la quantité de riz pour l'autoconsommation. Enfin, $9 \%$ sont disposés à s'inscrire dans le double objectif de l'autoconsommation et de la commercialisation. Dans ce dernier cas, le riz sera considéré comme une culture de rente. Aussi, l'utilisation des engrais chimiques pour accroître les rendements intéressent particulièrement cette dernière catégorie des enquêtés ( $9 \%)$.

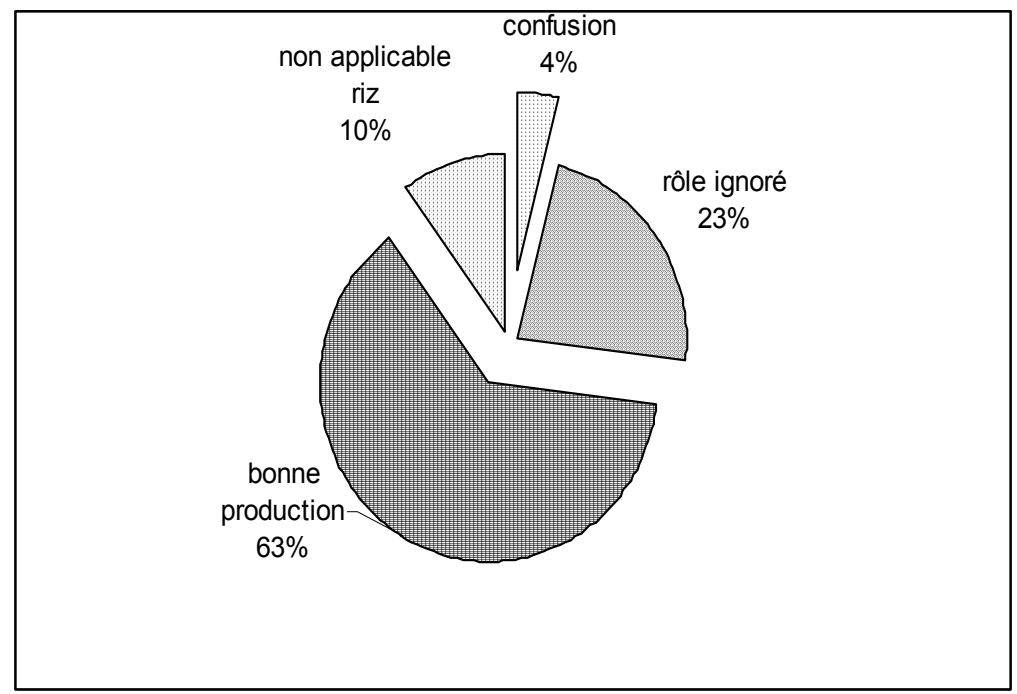

Figure 8 : Connaissance du rôle des engrais chimiques par les riziculteurs.

Farmer knowbedge of the importance of mineral in rice production.

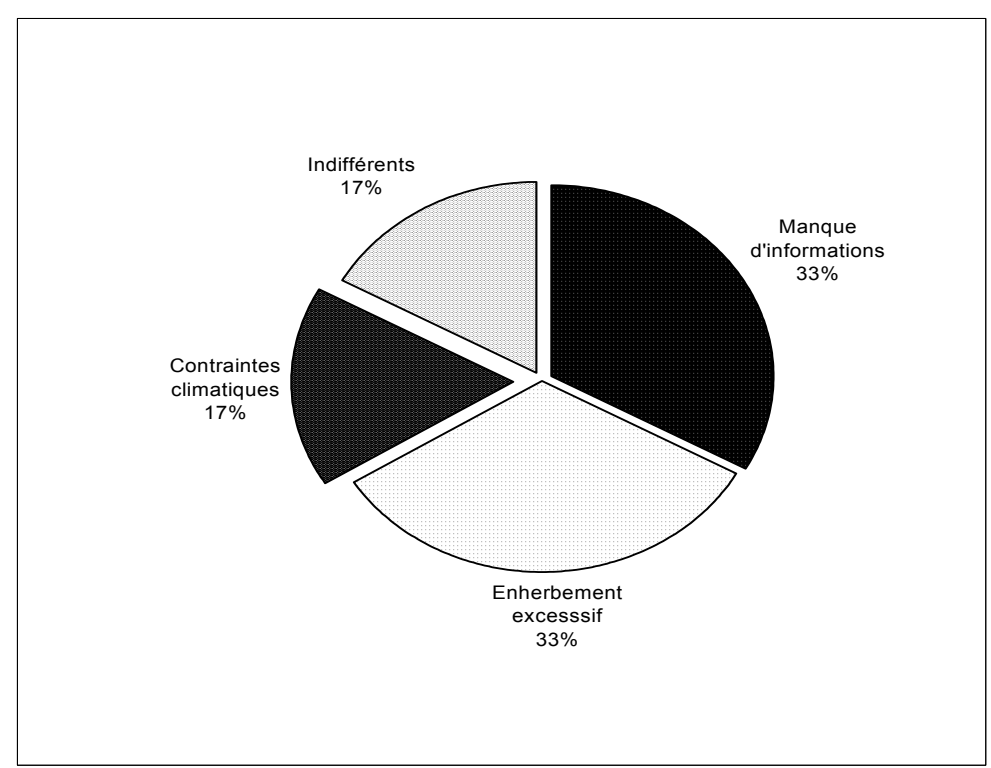

Figure 9 : Obstacles à l'utilisation des engrais chimiques en riziculture.

Problems enconntrod in the use of chemical fertilizers in rice cultivation. 


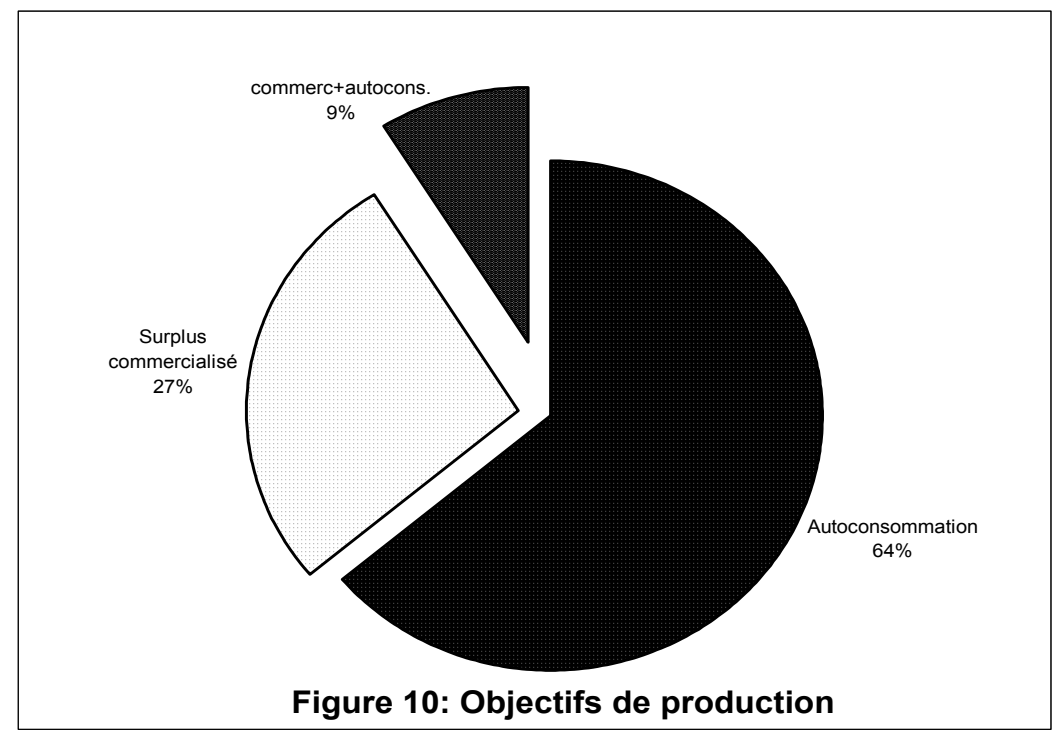

Figure 10 : Objectifs de production des riziculteurs.

Rice farmer production aims.

\section{DISCUSSION}

Les connaissances empiriques des paysans sur certains indicateurs de pauvreté du sol sont fondées sur des critères facilement vérifiables par la science. Ainsi, lorsqu'ils évoquent un sol qui colle c'est-à-dire argileux (taux d'argile supérieur à $30 \%$ ), celui-ci pourrait avoir non seulement une forte aptitude au compactage d'où sa cohésion, mais également la réserve en eau facilement utilisable du sol pourrait être faible (Gala, 2000). Egalement, la référence faite à la couleur du sol est-il un paramètre de classification présentement en vigueur dans le système mondial de détermination des aptitudes culturales (Nachtergaele, 2000).

Par ailleurs, il est révélé que les villageois cultivent préférentiellement les abords du village pour s'étendre progressivement vers les terres les plus éloignées (Charpentier et al., 1999). L'éloignement des parcelles cultivées serait donc un critère d'évaluation de la disponibilité en terre de riziculture. Ainsi, dans le village de Tézié, qui a été déjà présenté, lors d'une précédente enquête comme une zone de forte pression foncière, confirme cette réalité avec $14 \%$ des champs de riz pluvial situés à plus de $5 \mathrm{~km}$ du village ; par contre à Godoua où la pression foncière ne semble pas exister, la quasi-totalité des champs de riz se situe à moins de $5 \mathrm{~km}$ des lieux d'habitation.

La pression foncière observée déjà dans certaines zones de la Côte d'Ivoire notamment le centre du pays (Charpentier et al., 1999) a conduit les populations de ces zones à s'installer dans le centre ouest, région de la présente étude. La cause principale de cette émigration est la recherche de terre pour l'implantation des cultures industrielles que sont le café et le cacao. Ces cultures sont généralement consommatrices d'espace. Ce qui a pour incidence, la rareté des forêts primaires et des jachères de longues durées (de plus de 5 ans). Aussi, les riziculteurs sont-ils contraints à exploiter une même parcelle pendant 3 ans successivement, et cela, malgré la baisse certaine de la fertilité du sol qui se traduit par de faibles rendements (moins de 0,5t/ha).

Si l'on tient compte du fait que certains riziculteurs ne se fondent que sur des indicateurs particuliers comme par exemple la présence des lianes et des arbres avant la mise en valeur des jachères et face au raccourcissement de la durée de jachère qui est aujourd'hui de 2 à 3 ans et à la quasi-absence de forêts primaires, il devient important de déterminer les conditions d'une sédentarisation de l'agriculture vivrière encore itinérante et extensive sans apport d'intrants. La détermination de ces conditions nécessite, 
entre autres, la mise au point des techniques de restauration de la fertilité des sols pour l'obtention de rendements acceptables.

En effet, l'exploitation continue des terres avec pour seul moyen de restauration de la fertilité, la jachère naturelle, occasionne de fortes baisses de rendement de l'ordre de 30 à $75 \%$ dans la région de l'étude selon les agents de l'ODVL (communication orale). Cette baisse de rendement a été notée par ailleurs par l'ADRAO (1999) en culture continue de riz pluvial.

Pour compenser de telles pertes, il faut nécessairement un apport de fertilisants. Et les engrais chimiques peuvent dans ce cas jouer un rôle incontournable (Bationo et Somda, 1994). Mais la méconnaissance du rôle et des périodes d'application des engrais chimiques de même que leur cherté constituent des freins à leur adoption (Randrianarisoa et Minten, 2003).

Au regard des prix d'achat des engrais chimiques pratiqués actuellement en Côte d'Ivoire (240 FCFA/kg d'engrais), la somme de 4000 FCFA que les riziculteurs se disent disposés à débourser pour la fertilisation minérale équivaut seulement à environ $17 \mathrm{~kg}$ d'engrais chimique.

En faisant le rapport entre cette quantité d'engrais à la portée des paysans et la taille moyenne des champs de riz $(0,75 \mathrm{ha} /$ riziculteur $)$ de la zone d'enquête, l'on réalise que l'effort financier d'un riziculteur pour l'utilisation des engrais chimiques ne peut supporter que $23 \mathrm{~kg}$ d'engrais chimique par hectare de riz.

Cette dose de $23 \mathrm{~kg} / \mathrm{ha}$ est supérieure à celle que déclaraient les statistiques de la FAO (moins de $10 \mathrm{~kg}$ d'engrais par hectare) selon Stoorvogel et Smaling (1990) puis Van Reuler et Prins (1993).

Cela pourrait se justifier par l'augmentation de la valeur marchande du riz cultivé (Randrianarisoa et Minten, 2003).

En effet, la vente de production des nouvelles variétés de riz tels que les NERICAS sous forme de semence à 400FCFA/kg est un simulant pour l'adoption des engrais chimiques. II faut souligner que ce prix fort rémunérateur, risque toutefois de connaître un problème si le nombre de ceux qui ont la commercialisation des NERICAS sous forme de semence comme objectif de production augmente, surtout quand l'on considère que la filière de commercialisation est encore informelle (Diomandé, 1995). Pour cela, il faudrait que les services de vulgarisation tel que l'Agence Nationale de Développement Rural (ANADER) se rapprochent davantage des riziculteurs pour leur faire bénéficier des acquis de la recherche (Sokpoh, 1997) à travers des implantations de plusieurs parcelles de démonstration qui finiraient par convaincre tous les exploitants de l'importance des engrais chimiques. Cette vision est aussi partagée par les revendeurs de produits agrochimiques de la région d'étude.

Par ailleurs, comme alternative à la cherté des engrais chimiques, l'on devrait s'orienter également vers une fertilisation organo-minérale par l'utilisation des légumineuses qui sont ignorées des paysans (Bationo et Somda, 1994 ; Sokpoh, 1997, Bado, 2002).

\section{CONCLUSION}

Les enquêtes réalisées dans la région de Saïoua, au centre ouest de la Côte d'Ivoire, ont permis de se faire une opinion sur la problématique de l'utilisation des engrais chimiques en riziculture pluviale.

La pression sur les terres cultivées est aujourd'hui une réalité. Et la démographie galopante contribue, de manière significative, à la dégradation du sol. La durée des jachères n'étant plus suffisante (2 à 3 ans) pour assurer la restauration naturelle des terres, toute autre forme de fertilisation telle que l'utilisation des engrais chimiques s'avère nécessaire.

Le manque d'informations sur l'utilisation des engrais chimiques, la cherté des engrais, la pauvreté prépondérante du monde rural, le stress hydrique sont, entre autres, des facteurs qui amènent les paysans à utiliser de faibles quantités d'engrais en riziculture pluviale de plateau qui reste encore itinérante sur brûlis. Suite à l'action de certaines Organisations Non Gouvernementales (ONG), la fertilisation minérale en riziculture pluviale commence à prendre un essor dans la zone d'étude. Cela mérite d'être encouragée par des actions concertées, surtout que la dose moyenne que peut supporter le riziculteur de la zone est supérieure à la moyenne statistique de la FAO.

Au niveau de la recherche, il s'agira d'approfondir les travaux allant dans le sens de la détermination des doses d'engrais économiquement rentables selon d'une part, les zones agro-écologiques et, d'autre part, dans le respect des conditions financières des paysans qui ne bénéficient ni de subventions, ni de crédits. C'est pourquoi, les études en cours dont l'objectif principal est 
la détermination des doses fractionnées d'engrais doivent prendre en compte les divers types de riziculteurs et proposer des alternatives aux engrais chimiques comme par exemple l'utilisation des légumineuses.

\section{REFERENCES}

ADRAO. 1999. Synthèse sur la recherche rizicole en Afrique de l'Ouest $n^{\circ} 2$. Utilisation des légumineuses comme culture de couverture augmente la productivité du riz pluvial dans les systèmes de culture intensif à jachère courte. «http : /I www.warda.org».

ADRAO. 2002. Rapport annuel. «http : II www.warda.org».

Akanza P. K. et G.Yoro. 2003. Effets synergiques des engrais minéraux et de la fumure de volaille dans l'amélioration de la fertilité d'un sol ferrallitique de l'Ouest de la Côte d'Ivoire. Agronomie Africaine 15 (3) : 135 144.

Autfray P. et H. Gbakatchétché. 1994. Fixation de l'agriculture en zone forestière de Côte d'Ivoire. Synthèse de 4 années d'expérimentation sur les parcelles gérées par les paysans. P.E.S de Guemenedou-Gagnoa. Note technique IDESSA/CIRAD, Bouaké, Côte d'ivoire, $12 \mathrm{p}$.

Autfray P. et H. bakatchétché. 1998. Semis direct de cultures vivrières dans les couvertures végétales en zone forestière de Côte d'ivoire. In : F. Rassolo, M. Ronet (Eds.) Gestion agrobiologique des sols et des systèmes de cultures. Atelier International de Madagascar du 23 au 28 mars 1998. FOF/FA/ANAE/CIRAD. Antsirabé, Madagascar : pp 563-576.

Bado B. V. 2002. Rôle des légumineuses sur la fertilité des sols ferrugineux tropicaux des zones Guinéenne et Soudanienne du Burkina Faso - Thèse de Doctorat, Université de Laval, (Québec), 184 p.

Banque Mondiale. 1982. Rapport annuel. «http : // www.fao.org».

Bationo A. et Z. Somda. 1994. Gestion de la fertilité des sols. In : W. B. Hoognoed, M. C. Klaij (Eds.). Le travail du sol pour une agriculture durable, Cours de formation 4 - 13 juillet 1994. FAO, W.B. Hoogmoed M.C. Klaij. Niamey, Niger. «http : II www.fao.org».
Becker M. and P. Assigbé. 1995. Rice-based cropping systems research in west Africa. In : A. Cheneau-Loquay, A. Leplaideur (Eds.). Quel avenir pour les riziculteurs en Afrique de l'Ouest ? Proc. Intern. Coll., 4 - 7 april 1995, CNRS, CIRAD, Bordeaux, France : pp $77-80$.

Becker M. et D. Johnson. 1998. Legumes as dry season fallow in upland rice-based systems of West-Africa. Biologie and Fertility of soils $27: 358-367$.

Charpentier H., Doumbia S., Coulibaly Z. et O. Zana. 1999. Fixation de l'agriculture au Nord et au Centre de la Côte d'Ivoire : quels nouveaux systèmes de culture. Agriculture et Développement 21: 4 - 70.

Diomandé K. 1995. Dévaluation et autosuffisance alimentaire : le cas de la filière riz en Côte d'Ivoire. Séminaire mensuel. CIRESUniversité National, Abidjan, Côte d'Ivoire. $17 \mathrm{p}$.

Dupriez H. et $P$. De Leener. Agriculture tropicale en milieu paysan africain. Terres et vie, Nivelles, Belgique. 280 p.

Eponou T. 1983. Farm level analysis of rice production systems in Northwestern Ivory Coast. Dissertation for Degree of Ph.D., Michigan State University, USA, 197 p.

FAO. 2002. Promising technologies for rice production in western end central Africa. Rapport interne : pp 12 - 13.

FAO. 2004. FAO statistics database. Rome «http : Il www.fao.org".

Gala B. T. J. 2000. Détermination des caractéristiques physiques, chimiques et hydrodynamiques des sols pour l'optimisation de l'irrigation en culture de canne à sucre. Mém. Diplôme d'Agronomie Approfondie, Option Pédologie. Ecole Supérieure d'Agronomie de Yamoussoukro. (Côte d'lvoire). 69 p.

Gnahoua G. M. 1997. Etude de la flore adventice des cultures après jachère améliorée dans la région d'Oumé (Côte d'Ivoire). In : C. Floret et $\mathrm{R}$. Pontanier (Eds.). La jachère et maintien de la fertilité, Actes de l'atelier International, Bamako, 2 - 4 oct. 1997, Dakar, Coraf / IRD / Union européenne, Paris , France, $146 \mathrm{p}$.

Harmand J. M. et P. Ballé. 2001. La jachère agroforestière (arborée et arbustive) en Afrique tropicale. In : J. Libbey Eurotext (Eds.). La jachère en Afrique tropicale : De 
la jachère naturelle à la jachère améliorée. Le point des connaissances, John Libbey, (2), Paris, France : pp 265 - 292.

Hirsch R. D. 1984. La riziculture ivoirienne : Diagnostic et condition préalable d'une relance. Multigr. Côte d'Ivoire. $34 \mathrm{p}$

Kéli J. Z., Obouyeboua S. et B. Zéhi. 1990. Perspectives de stabilisation des systèmes de cultures à base d'hévéa en basse Côte d'Ivoire. In : M. Diomandé (Eds.). Défis de la stabilisation des systèmes traditionnels de cultures en Côte d'Ivoire. Actes du Troisième Atelier OFRIC du 21 au 23 juin 1990, Bouaké, Côte d'Ivoire : pp 52 - 57.

Kouadio A. 2003. Arrières effets du niébé (Vigna unguiculata) et du soja (Glycine max) sur les céréales : cas du riz pluvial et du maïs ; Mém. de BTS Agricole. INFPA, Abengourou, Côte d'Ivoire, $21 \mathrm{p}$.

Melendez J., Becker M. and D. Johnson. 2003. Maintaining the Yield of Upland Rice under Intensified Land Use in Slash and Burn Systems of West Africa. «http : // www.pitros.uni-bonn.de».

Nachtergaele O. F. 2000. New developments in soil classification : the World Reference Base for Soil Resources. Quatorzième Réunion du Sous-Comité ouest et centre africain de corrélation des sols pour la mise en valeur des terres Abomey, Bénin, du 9 au 13 octobre 2000. FAO. "http : II www.fao.org».

N'Cho A, et Konaté I. 2001. Rapport annuel, OVDL.Multigr. $36 \mathrm{p}$.

N'Cho A, et Konaté I. 2004. Rapport annuel, OVDL.Multigr. $39 \mathrm{p}$.

Norman J. C. and Otoo E. 2003. Rice development strategies for food security in Africa. In Sustainable rice production for food security. Proceedings of the $20^{\text {th }}$ session of the international rice commission. FAO, Rome. «http : // www. Aatf-africa.org».

Randrianarisoa J. C. et Minten B. 2003. Accessibilité et utilisation des engrais chimiques à Madagascar, Conférence «Agriculture et pauvreté». FOFIFACORNELL-CNRADR- Programme ILO, Antanarivo, $6 \mathrm{p}$.

Riquier J. 1971. Rice cultivation. Notes on agroecology of rice and soil suitabilitability for rice cultivation in West Africa. FAO, Rome, Italie : pp 6 - 10.

Ryser J. et J. Pittet. 2002. Valeur fertilisante azotée du pois et du soja dans la rotation des cultures : Résultats d'un essai en lysimètres. Revue suisse d'agriculture, 34 (3) : 111 - 114.

Saragoni H., Poss R., Marquete J., et E. Latrille. 1992. Fertilisation et succession des cultures vivrières au sud du Togo : synthèse d'une expérimentation de longue durée sur terre de barre. Agronomie Tropicale 40 (2) : $107-120$.

Sokpoh G. B. 1997. Impact de la dévaluation du franc CFA sur l'utilisation des engrais minéraux et nouvelles stratégies de fertilisation au Togo. IFDC-Afrique, École Supérieure d'Agronomie, Lomé, Togo

Stoorvogel et Smaling. 1990. Review on soil assessment nutrientdepletionand requirements. Approach and methodology. FAO. Rome. «http : /l www.warda.org»

Van Reuler H. et W. H. Prins. 1993. Rôle de la fertilisation pour assurer une production durable des cultures vivrières en Afrique subsaharienne. The Deutch Association of Fertilizer Association (VKP), Leidschendam, Pays-Bas, 259 p. 